\title{
Reconnecting With Customers through Culture - Revisiting the Concept of Cultural Diversity in Luxury Fashion Brands
}

\author{
Jenny Ma* \\ University of Greenwich, United Kingdom
}

*Corresponding author: Jenny Ma, Department of Marketing, Events \& Tourism, University of Greenwich, Old Naval College, Park Row, SE10 9LS, London, United Kingdom.

Received Date: April 09, 2020

Published Date: April 16, 2020

\section{Opinion}

After Prada began manufacturing masks and LVMH started producing hand sanitizer in some of their perfume factories, most of us realised that the Covid-19 pandemic would not only force many businesses to adapt to the unprecedented and challenging new situation, but also lead to a change in our consumption activities. For example, it has been suggested that consumers might reconsider certain luxury consumption activities as the global pandemic may encourage consumers to take on a new set of values when spending money [1]. Therefore, the key challenges facing luxury brands after this pandemic will be to prove the value of their brands to their target customers and to attempt to reconnect with them. Continuing to embrace the concepts of sustainability and diversity will thus still remain the central brand strategy for luxury fashion brands.

Promoting diversity is not a new concept in luxury fashion. From the perspectives of brand management, customer relationship and corporate social responsibility (CSR), cultural diversity has been frequently mentioned in the fashion news. However, there are still areas in which brands can improve. Firstly, diversity is not merely a "box-ticking" exercise. It seems to be accepted in the field that diversity should be achieved simply by reaching a target figure, whereas in fact it is the quality of their approach to diversity that can truly make an impact on a brand. For instance, this is how the "diversity" of Paris Fashion Week was observed [2]: "Although Paris has been slow to adapt to calls for more diversity on runways, a few labels made efforts. Chanel featured a couple of real-bodied models, and Miu walked several black models, a year after its sister brand Prada suffered withering criticism for selling monkey charms that evoked blackface and formed a diversity council to address the issue." From this report, neither the meaning of diversity nor how the issue of diversity specifically links to the brands and their collections are made clear. We only see a superficial sense of diversity, perhaps an understanding of "diversity" that has its roots in trendy conversations on social media. According to scholars, this is a "globally circulating rhetoric of diversity" [3], and while it may have helped to promote the institutional inclusion of more models from other ethnic backgrounds and lead brand managers to believe that their customers viewed their brands as socially progressive, this is obviously not a holistic approach. The use of certain ethnic minority models, as reported during Paris Fashion Week, may not in fact resonate for a large proportion of the brands' customer base, such as customers from Asia and the Middle East. One could almost argue that such "diversity" is based on the perspective of the Western world, as has been the case with similar issues in other forms of marketing communications. Many brands now focus on representing certain groups that were previously discriminated against in Western society while still excluding other cultures.

This is understandable. There will always be an ethnic group that a casting agency fails to include, and after all, customers are unlikely to remember how many "diverse" models are used in the show. The key point is whether this form of brand communication is effective in making the target customers feel closer to the brand. Arguably, this approach seems to have little impact on whether consumers perceive the brand to be truly diverse or not. Furthermore, studies have also shown that the way in which consumers respond to the choice of models may differ depending on the context, and preexisting perceptions of the brands influences how consumers respond to the use of diverse models in advertising [4,5]. 
Therefore, luxury fashion brands must rethink their strategy with regards to diversity. They must first address consumer perceptions of their brands and how culturally sensitive they are perceived to be, in order to add value and increase the effectiveness of their diversity practices. As mentioned above, brand managers must carefully consider an appropriate context for their brands models from different ethnic backgrounds. Culture itself is a context, in which people have their shared memories of language, rituals and customs. We must understand our customers' cultures in order to effectively communicate with them through our shared memories. In recent years, another popular practice through which luxury brands have sought to address the issue diversity is to hire chief diversity officers, such as Fiona Pargeter from Chanel, and Renée E Tirado from Gucci. Similar to the use of models, this effort to address diversity, while laudable, is not the only way to achieve a holistic approach. If we can consider a culture as a context, we must acknowledge that we one manager cannot possibly understand all contexts. The brands must seek help from their customers to guide them and inspire them in how to embrace local cultures while retaining their existing brand image. Consumer value co-creation is a useful concept here. Luxury fashion brands already have experience of collaborating with local artists, but consumer value co-creation will be more effective in terms of understanding cultural contexts and forging an emotional connection with customers.

The notorious D\&G campaign in China in 2019 is an example of the box-ticking approach to tackling diversity. The campaign did feature a Chinese model and include details of Chinese culture (or what they thought were typical of Chinese culture) by depicting a woman using chopsticks. However, a lack of understanding of the target consumer in the context led a disastrously failed attempt at humour. The advertisement, which featured a model eating pizza with chopsticks, was supposed to demonstrate the integration of two cultures. However, this is not how luxury brand consumers in China want to be seen, preferring to be seen as trendy global consumers who are sophisticated enough to embrace other cultures.
Finally, it is important for the brand to truly understand the meaning of "diversity" and "luxury fashion" in different cultures, so that the brand can start to successfully manage its brand identity to combine these two elements. Of course, part of the appeal of luxury fashion lies in the products' cultural independence and their ability to reflect a globally shared desire for prestige, inspiration and highquality. Nevertheless, we should also keep in mind that the reasons for purchasing luxury fashion items are already diverse, such as a desire for discreet status symbols, not wishing to lose face, social conformity or self-rewarding. Making the brand's identity truly meaningful to a wide range of luxury customers while at the same time maintaining its authenticity is the true definition of diversity. Brand managers must develop a long-term strategy for diversity in order to establish a significant emotional connection with local customers in different cultural contexts. Focusing on numbers alone may be trendy, but being merely trendy is never enough for luxury fashion brands - they must aim to be inspirational.

\section{Acknowledgement}

None.

\section{Conflict of Interest}

No conflict of interest.

\section{References}

1. (2020) University of Illinois at Urbana-Champaign, News Bureau. Value instantiation' key to luxury brands' and social responsibility. Science Daily.

2. Binkley C (2020) In Paris, uncertainty overshadows sustainability and diversity.

3. Nicolas W (2017) The Promise of Diversity. How Brazilian brand capitalism affects precarious identities and work. Bielefeld: Transcript.

4. Karande K (2004) Minority response to ethnically similar models in advertisements: an application of accommodation theory. Journal of Business Research 58(11): 1573-1580.

5. Appiah O, Liu YI (2009) Reaching the Model Minority: Ethnic Differences in Responding to Culturally Embedded Targeted- and Non-Targeted Advertisements. Journal of Current Issues \& Research in Advertising 31(1): 27-41. 